\title{
THE EFFECT OF SILICA BASED NANOCOMPOSITE POUR POINT DEPRESSANT ON THE WAXY CRUDE OIL OF NORTH-EAST INDIA
}

\author{
Rituraj Singh \\ Department of Petroleum Engineering, \\ DUIET, Dibrugarh University, Assam, India
}

\begin{abstract}
In the aura of this research we developed the grafted nanocomposite pour point depressant by culmination of a set of monomers namely acrylamide, maleic anhydride, styrene, and octadecyl methacrylate and further grafted to nano silica for improving the flow properties and thereby decrease the temperature of pour point value of the NorthEast Indian waxy based crude oil. Moreover, to emphasize and understand the central effects of different concentrations of synthesized nanocomposite pour point depressants on the pour point of waxy crude oil, several important experiments were undergone and later its results were compared with the commercial pour point depressant. In addition, the rheological props of the sample crude were also analyzed with and without additives. The results shows that the synthesized nanocomposite has more effectively reduced the viscosity as well as pour point of the sample to desired value when compared to that of the commercially used pour point depressant.
\end{abstract}

Keywords: Grafted Nanocomposite, Pour Point Depressant, Wax, Crude Oil, Rheology, Nano silica, Viscosity

\section{INTRODUCTION}

The crude of the North-East Indian states like Assam has high percentage of paraffins mix and is saturated with wax. This property of the crude causes development of high pour point and viscosity which create severe flow related problems during the pipeline transportation from upstream to downstream. As soon as the temperature falls below the specific Wax Appearance Temperature (WAT) of the crude oil, paraffin present in it starts depositing on the inner walls of pipelines and creates obstruction to the crude flow. This deposition has non-repairable effects causing blockage to the fluid flow which may be fatal and cause pipe rupture. It has impacts on both economy of the transporting company as well as the environment. $[1,2]$.

Various attempts have been sighted before to cope with this prevailing issue such as the use of chemical inhibitors like addition of polymers to transporting crude oil. Polymers have been widely in use in perspective of the modern world due to their cost effectiveness and simple manufacturing process. A common use of polymers is the

\author{
Prasenjit Talukdar \\ Department of Petroleum Engineering, \\ DUIET, Dibrugarh University, Assam, India
}

development of Polymeric Pour Point Depressants (PPDs) to improve the rheological properties of waxy crude oil. Out of all these, the comb-like copolymers type and the EVA type PPDs has excellent adaptation and pour point depressing properties and therefore commonly recommended for use in the crude oil transportation. These two forms of polymeric PPDs often develop polar groups and nonpolar carbon chains. The non-polar constituent will help in paraffin precipitation through nucleation and cocrystallization, while the polar groups will create a repulsive effect towards wax crystal deposition and slowdown their growth. Thereby altering the structural framework and wax crystal growth [3, 4].

In recent years researchers have developed interest in developing organic-inorganic Nano composites as they have improved properties such as improvement of flow performance of traditional polymeric PPDs, improvement in mechanical and thermal properties. These Nano composites are formed by little dispersion of non-organic particles into a polymeric matrix. One of the widely used additive is Smectite clay $[5,6]$.

The dispersed polymeric clay is divide into two forms, intercalated (the registry of clay layer is maintained) and exfoliated (the registry of clay layer is lost). The effect of the exfoliated clay when held in polymers produces high performance Nano composite owing to the abundance of a large number of clay that offers a large area layer for interaction with the polymeric matrix [7]. Various researchers developed PMMA-montmorillonite (MMT) Nanohybrid to improve flow properties and further investigated that exfoliated has effectively improved rheological characteristics of crude oil. Yao et al. compared polyoctadecrylate and polyoctadecylacrylate-clay Nano composite as PPD. It was seen that the addition of modifies clay to polyoctadecrylate improved the rheology properties of crude oil, while the wax crystals develop at elevated temperature $[8,9]$.

In this research, of a set of monomers namely acrylamide, maleic anhydride, styrene, and octadecyl methacrylate and further grafted to nano silica and characterized by FESEM as well as FTIR analysis. Then, the effect of different concentrations of PPD on pour point were studied. Finally, a thorough investigation of the waxy crude oil's rheology was accomplished using the commercial and synthesized nanocomposite PPD for its suitability in pipeline transportation of waxy crude oil. 


\section{International Journal of Engineering Applied Sciences and Technology, 2021 Vol. 5, Issue 9, ISSN No. 2455-2143, Pages 147-151 \\ Published Online January 2021 in IJEAST (http://www.ijeast.com)}

\section{EXPERIMENTAL STUDIES}

\subsection{Materials}

The crude oil sample used for the present study was taken from the North-Eastern oil fields, Oil India Limited (OIL), India. Nano-silica oxide powder was bought from SRL Pvt. Ltd. (Mumbai, India). Methacrylate, acrylamide monomers were bought from SigmaAldrich (Kolkata, India). Maleic anhydride, ethanol, azobisisobutyronitrile, xylene and styrene were from the Central Drug House (P) Ltd. (New Delhi, India).

\subsection{Characterization Methods of Crude Oil}

\subsubsection{Pour point, Water content and API gravity}

The pour point of a crude oil is the temperature below which the crude loses its flow properties due to wax development. ASTM D9706.11 is used for measuring the temperature of pour point of the samples of crude oils. For this method, standard ASTM apparatus for pour point which includes test jar, thermometer, bath, and jacket was used for the determination of pour-point. The sample was heated and the pour point was obtained at 45 to $48^{\circ} \mathrm{C}$ and then cooled down and

Finally checked at an interval of every $3^{\circ} \mathrm{C}$. When oil flow ceases on tipping the jar used for test horizontally, the particular temperature is recorded as pour point. It is used for quality estimation of the crude $[10,11,12]$.

Values of API gravity of every crude were estimated using specific gravity values at $40^{\circ} \mathrm{C}$. Water content determination was done by centrifuge method (ASTM D 96-58 T). For this method, $25 \mathrm{ml}$ sample and $25 \mathrm{ml}$ of toluene were mixed thoroughly in centrifuge tube and this centrifuge tube is whirled inside the centrifuge set up at desired speed for 10 minutes. After whirling, two layers develop and the amount of water is estimated using the calibration at the bottom of the centrifuge tube [2].

\subsubsection{Wax Content and SARA distribution}

Wax content determination: take oil sample in a beaker followed by stirring with n-pentane in a mixture ratio of 1:20 (w/v) (weight per unit volume) for an interval of $30 \mathrm{~min}$. Add acetone over the mixture $\&$ freeze overnight. Then, solid organic wax was filtered under vacuum in a Buchner funnel using Whatman filter paper 934. Using hot hexane, the wax is then filtered out [2].

For SARA distribution, crude oil and n-heptane are mixed in the ratio $1: 30(\mathrm{w} / \mathrm{v})$, and heated to $40{ }^{\circ} \mathrm{C}$ and then cooled to ambient conditions. It was followed by vacuum filtration followed by hot toluene extraction. Maltene (residual filtrate solution) is analyzed to be rich in non-asphaltene constituents like saturates, resins etc. with partially wetting the silica gel by heptane a gel column is generated. For complete extraction of saturates, the Maltene is now allowed to pass through the gel with an extra dose of heptane.

For extraction of aromatics, toluene is allowed to pass over the bed. Resin elution is a stepwise process: First 50:50 (v/v) toluenemethanol mixture flowed, followed by 50:50 (v/v) methanolchloroform solution, next chloroform and at the last acetonitrile was poured over the bed. Elutes from separate container were collected and the solvent was evaporated to extract solid resins $[2,12]$.

\subsection{Synthesis of the grafted silica-based nanocomposite PPD}

Firstly, the surface of nano-silicon oxide was modified by using KH570 [13]. Then, acrylamide, maleic anhydride, styrene, and octadecyl methacrylate in xylene taken in a molar ratio of 1:2:1:5 and mixed together to get homogeneous solution. Afterwards, this solution was taken in a graduated $500 \mathrm{ml}$ three necked round bottom flask. The flask was furnished with an electrically operated sensitive magnetic stirrer (Tarsons, Model: Spinot Digital) and kept in an oil bath maintained at a temperature of $60{ }^{\circ} \mathrm{C}$, with constant stirring. Later, $2.5 \mathrm{~g}$ of modified nano silicon oxide was added to the homogeneous solution and continued to heat at the same temperature $\left(60{ }^{\circ} \mathrm{C}\right)$ with constant stirring $(400 \mathrm{rpm})$ for $30 \mathrm{~min}$. Afterwards, the solution temperature was increased slowly to $80{ }^{\circ} \mathrm{C}$ with the continuation of the reaction for another 5 hours holding the stirring speed and temperature constant. Throughout the reaction, a stream of nitrogen gas is passed. After the completion of reaction, the reaction mixture was cooled to room temperature and centrifuged at 2000 rpm for 20 minutes to obtain the precipitate. The product (grafted nanocomposite) was finally washed with acetone and dried in vacuum oven at $40^{\circ} \mathrm{C}$ for 6 hours $[6,7,13]$.

\subsection{Characterization of grafted nanocomposite PPD}

Fourier transform infrared (FTIR) spectra of various samples were recorded on PerkinElmer FTIR spectrometer (model Spectrum Two; PerkinElmer, Inc., Waltham, MA, USA) and range for the above measurements is $450-4000 \mathrm{~cm}^{-1}$. The surface morphology of modified and unmodified nano silica and synthesized nanocomposite were analyzed in Field-emission scanning electron microscopy (FESEM) Supra 55 model (Carl Zeiss, Germany) with Air Lock chamber in powdered form.

\section{RESULTS AND DISCUSSION}

\subsection{Characterization of waxy Crude Oil}

As per the specifications laid by API, the crude's API gravity simply indicates it is a heavy crude. The sample crude has been investigated to be highly waxy and can be correlated to its high pour point. The high pour point of this crude has negatively impacted its transportation due to the formation of wax layer on pipelines and hindrance in flow.

Table 2 shows SARA analysis results of the crude oil which reflects very high saturate content. High crude viscosity is simply due to this high saturate fraction. Asphaltene content is low whereas the resin content is high so the resin to asphaltene ratio is high. Greater this ratio, maximum is the asphaltene stability and thus minimum are the chances of asphaltene deposition [12].

\subsection{Characterization of synthesized nanocomposite PPD}

The nanocomposite structure was confirmed by FTIR spectroscopy. The FTIR spectra of modified and unmodified nano $\mathrm{SiO}_{2}$ and nanocomposite are shown in Figure 1. These spectra are quite consistent with those presented in the literature $[6,7,13]$. 


\section{International Journal of Engineering Applied Sciences and Technology, 2021 \\ Vol. 5, Issue 9, ISSN No. 2455-2143, Pages 147-151 \\ Published Online January 2021 in IJEAST (http://www.ijeast.com)}

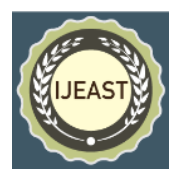

Table 1: Characteristic properties of crude oil

\begin{tabular}{|c|c|}
\hline Parameter & Observed Value \\
\hline API Gravity & 26.8 \\
\hline Pour Point & $36^{0} \mathrm{C}$ \\
\hline Wax Content $(\%(\mathrm{w} / \mathrm{w}))$ & 15.5 \\
\hline Water Content $(\%(\mathrm{v} / \mathrm{v}))$ & 2 \\
\hline
\end{tabular}

The IR spectra of unmodified nano $\mathrm{SiO}_{2}$ display a broad adsorption band at $3442 \mathrm{~cm}^{-1}$, due to the stretching frequency of the $\mathrm{OH}$ group and a bending peak at $1650 \mathrm{~cm}^{-1}$ attributable to $\mathrm{H}-\mathrm{O}-\mathrm{H}$ stretching vibration. The absorption band sought at $1120 \mathrm{~cm}^{-1}$ represents stretching of Si-O-Si and symmetric vibration at $470 \mathrm{~cm}^{-1}$ for $\mathrm{Si}-\mathrm{O}-\mathrm{Si}$ group. In the case of modified nano- $\mathrm{SiO}_{2}$ the bands at $2860 \mathrm{~cm}^{-1}$ and $2924 \mathrm{~cm}^{-1}$ are for the asymmetric and symmetric stretching vibration peaks of the $\mathrm{C}-\mathrm{H}$ bond. The bands at $3450 \mathrm{~cm}^{-1}$ attributes to $\mathrm{Si}-\mathrm{OH}$ group which indicates the surface of $\mathrm{SiO}_{2}$ was successfully modified [14].

Table 2. SARA analysis of crude oil sample

\begin{tabular}{|c|c|}
\hline Components & Amount $(\%(\mathrm{w} / \mathrm{w}))$ \\
\hline Saturate & $52 \%$ \\
\hline Aromatic & $14 \%$ \\
\hline Resin & $8 \%$ \\
\hline Asphaltenes & $0.5 \%$ \\
\hline Resin: Asphaltenes & $11.5 \%$ \\
\hline
\end{tabular}

Figure 1: FTIR of umodified nano $\mathrm{SiO}_{2}$, modified nano $\mathrm{SiO}_{2}$ and Grafted nanocomposite

Field-emission scanning electron microscopy (FESEM) (Figure 2) was used for the investigation of morphological characteristics of unmodified nano $\mathrm{SiO}_{2}$, modified nano $\mathrm{SiO}_{2}$ and synthesized Grafted nanocomposite. It has been observed that before modification nano $\mathrm{SiO}_{2}$ is having irregular morphology. After modification, the

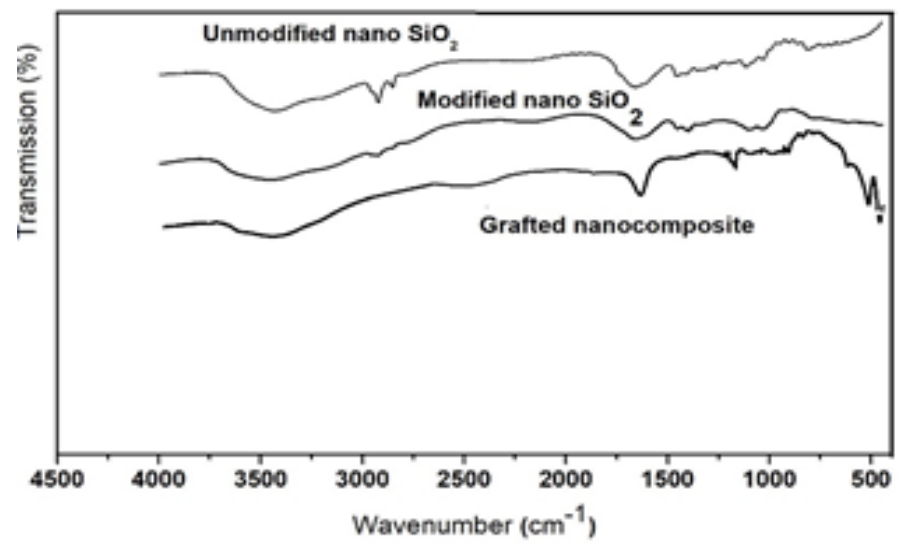

irregular appearance of $\mathrm{SiO}_{2}$ nanoparticle was reduced. This observation suggests that hydroxyl groups present on the surface of nano- $\mathrm{SiO}_{2}$ particles being replaced by organic groups. The morphology of modified nano- $\mathrm{SiO}_{2}$ was changed after grafting and exhibited better dispersibility and uniform particle size. This observation suggests that grafting of monomers affect the

morphological arrangement of nano- $\mathrm{SiO}_{2}$. This suggest that the nanocomposite may be formed.

Table 3. Effect of PPDs on pour point of waxy crude oil

\begin{tabular}{|c|c|c|}
\hline $\begin{array}{c}\text { Concentration of } \\
\text { PPD } \\
(\mathrm{ppm})\end{array}$ & \multicolumn{2}{|c|}{ Pour point in ${ }^{\circ} \mathrm{C}$ treated with } \\
\cline { 2 - 3 } & $\begin{array}{c}\text { Commercial } \\
\text { PPD }(\mathrm{C} 1)\end{array}$ & $\begin{array}{c}\text { Synthesized } \\
\text { PPD }(\mathrm{S} 1)\end{array}$ \\
\hline 0 & 36 & 36 \\
\hline 250 & 33 & 30 \\
\hline 500 & 29 & 25 \\
\hline 750 & 27 & 22 \\
\hline 1000 & 31 & 24 \\
\hline
\end{tabular}

3.3 Effect of the synthesized (S1) and Commercial (C1) additives on pour point of the crude oil

The effect on pour point of the waxy crude oil treated with and without PPD are presented in Table 3 . The results are indicating that the initially pour point of crude oil was high which results the wax accumulation in the pipelines and crude movement hindrance. After treated with PPD the pour point decreased but the performance of synthesised nanocomposite PPD (S1) is highly effective than the commercial PPD (C1). The effect of PPDs with change of concentration were also measured which provide the optimum concentration of synthesized PPD at which the lowest pour point value was observed. As the concentration of PPDs increased the PPDs crystals are started the linkage with wax which results the decrease the pour point of crude oil [2].
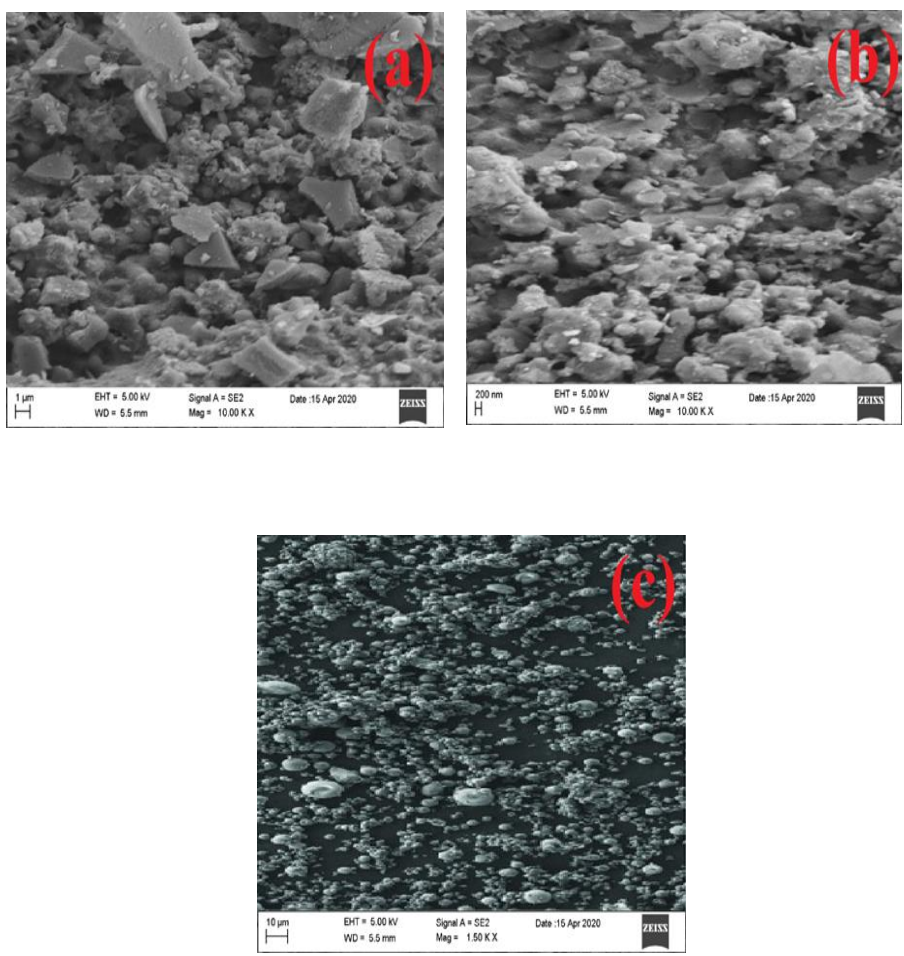

Figure 2: FESEM of unmodified nano $\mathrm{SiO}_{2}$, modified nano $\mathrm{SiO}_{2}$ and Grafted nanocomposite 


\section{International Journal of Engineering Applied Sciences and Technology, 2021 \\ Vol. 5, Issue 9, ISSN No. 2455-2143, Pages 147-151 \\ Published Online January 2021 in IJEAST (http://www.ijeast.com)}

\subsection{Effect of the synthesized (S1) and Commercial (C1) additives on Rheology of the crude oil}

The effect of PPD on rheology of crude oil are shown in Figure 3 and Figure 4 at $30^{\circ} \mathrm{C}$ and $20^{\circ} \mathrm{C}$ respectively. Rheological studies were study at $750 \mathrm{ppm}$ of conventional and synthesized PPD. $7500 \mathrm{ppm}$ is the optimum concentration obtained for the lowest pour point of the crude oil. The rheological studies showed that the viscosity is increased with lowering the temperature because of crystallisation of wax molecules and viscosity is decreased with increase of shear rate because of wax molecules were not stabilized at higher shear rate. The results were also indicating that the viscosity was much more reduced when treated with synthesized nanocomposite PPD comparatively than the commercial PPD. So, the synthesized nanocomposite PPD is more effective than commercial PPD.

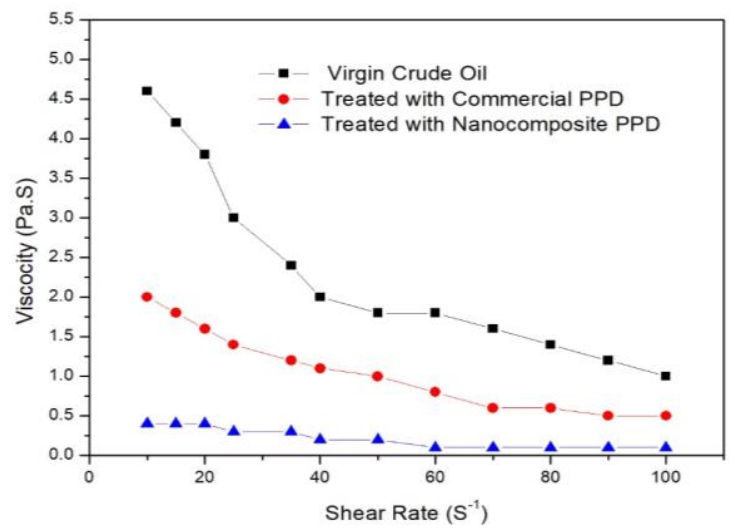

Figure 3: Rheology of virgin and PPDs treated Crude Oil at $30^{\circ} \mathrm{C}$

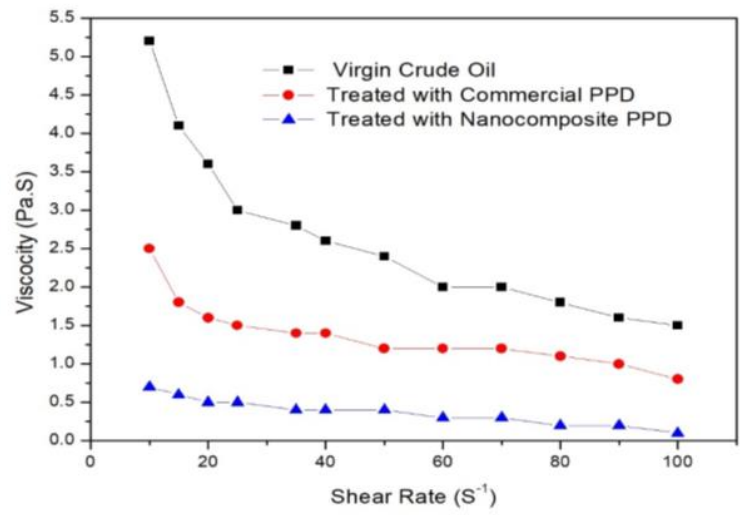

Figure 4: Rheology of virgin and PPDs treated Crude Oil at $20^{\circ} \mathrm{C}$

\section{CONCLUSION}

A novel nanocomposite PPD was synthesized for improve the flow properties and the following conclusions were obtained:

1. The nanocomposite PPD was prepared finally, well characterized and its features on application for improving the pour point and flow of the waxy crude.
2. FESEM and FTIR revealed that the formation of nanocomposite PPD may be due to strong polymer-clay interaction.

3. After treated with PPD the crude's pour point decreased but the performance of synthesised nanocomposite PPD (S1) is highly effective than the commercial PPD (C1).

4. The viscosity of waxy crude oil was much more reduced when treated with synthesized nanocomposite PPD comparatively than the commercial PPD.

\section{ACKNOWLEDGMENT}

The authors would like to gratefully acknowledge DUIET, Dibrugarh University for providing necessary laboratory facilities to carry out this work. Also, they acknowledge National Project Implementation Unit (NPIU) for providing financial support under CRS project (Project ID: 1-5716866523) to carry out the research works.

\section{REFERENCES}

[1] Alimohammadi, S.; Zendehboudi, S.; James, L. (2019). A comprehensive review of asphaltene deposition in petroleum reservoirs: Theory, challenges, and tips. Fuel 2019, 252, 753791.

[2] Deka, B., Sharma, R., Mandal, A., Mahto, V. (2018). Synthesis and evaluation of oleic acid based polymeric additive as pour point depressant to improve flow properties of Indian waxy crude oil. J. Pet. Sci. Eng., 2018, 170, 105-111.

[3] Saniere, A.; Hénaut, I.; Argillier, J. F. (2004). Pipeline transportation of heavy oils, a strategic, economic and technological challenge. Oil \& Gas Science and Technology 2004, 59(5), 455-466.

[4] Hasan, S. W.; Ghannam, M. T.; Esmail, N. (2010) Heavy crude oil viscosity reduction and rheology for pipeline transportation. Fuel 2010, 89(5), 1095-1100.

[5] Zhang, H.; Jiang, R.; Qi, X.; Yang, M.; Bi, Y.; Yu, S.; Yu, P.; Zhang, C. (2015). Preparation of Nano PSMA-AM/SiO2 Composite and Its Application in Pour Point Depression and Viscosity Reduction of Heavy Oil. New Chemical Materials 2015, 43(11), 210-212.

[6] Zhang, Y.; Zhu, H.; Wang, F.; Yi, H.; Wei, Y.; Zhang, L. (2009) Study on Modified $\mathrm{NanoSiO}_{2} /$ Sulfonated Polystyrene-Maleic Anhydride Viscosity Reducer. Functional Materials 2009, 40(3), 498-500.

[7] Corredor, L. M.; Aliabadian, E.; Husein, M.; Chen, Z.; Maini, B.; Sundararaj, U. (2019). Heavy oil recovery by surface modified silica nanoparticle/HPAM nanofluids. Fuel 2019, 252, 622-634.

[8] Zhen, Z.; Jing, G.; Sun, Z.; Zheng, C. (2018). Nano-composite pour point depressants in improving the rheology of waxy crude oil. Petroleum Science and Technology 2018, 36(17), 13251331.

[9] He, C.; Ding, Y.; Chen, J.; Wang, F.; Gao, C.; Zhang, S.; Yang, M.. (2016). Influence of the nano-hybrid pour point depressant on flow properties of waxy crude oil. Fuel 2016, 167, 40-48. 


\section{International Journal of Engineering Applied Sciences and Technology, 2021 Vol. 5, Issue 9, ISSN No. 2455-2143, Pages 147-151 \\ Published Online January 2021 in IJEAST (http://www.ijeast.com)}

[10] Alghanduri, L. M.; Elgarni, M. M.; Daridon, J.-L.; Coutinho, J. A. (2010). Characterization of Libyan waxy crude oils. Energy \& Fuels 2010, 24, (5), 3101-3107.

[11] Taraneh, J. B.; Rahmatollah, G.; Hassan, A.; Alireza, D. ( 2008) Effect of wax inhibitors on pour point and rheological properties of Iranian waxy crude oil. Fuel processing technology 2008, 89, (10), 973-977.

[12] Nemirovskaya, G.; Emel'yanova, A.; Ashmyan, K. (2005) Methods of analysis of high-wax crude oils. Resins, asphaltenes, paraffin waxes. Chemistry and technology of fuels and oils 2005, 41, (3), 236-240.

[13] Mao, J.; Kang, Z.; Yang, X.; Lin, C.; Zheng, L.; Zuo, M.; Mao, J.; Dai, S.; Xue, J.; Ouyang, D. (2020). Synthesis and Performance Evaluation of a Nanocomposite Pour-Point Depressant and Viscosity Reducer for High-Pour-Point Heavy Oil, Energy Fuels, 2020 34(7), 7965-7973.

[14] Zhang, F.; Wang, B. (1995). Study on the Mechanism of Several Crude Oil Pour Point Depressants by Infrared Spectroscopy and X-ray Diffraction. Oilfield Chemistry 1995, 12(4), 347-352. 